\title{
Sckences \\ Amiodarone in the treatment of refractory supraventricular and ventricular arrhythmias
}

\author{
P. J. WHEELER* \\ B.Sc., M.B., M.R.C.P.
D. V. INGRAM $\dagger$
F.R.C.S.

R. PURITZ*

M.B., M.R.C.P.
D. A. Chamberlain*
M.D., F.R.C.P.

\author{
*Department of Cardiology, Royal Sussex County Hospital, Brighton, and \\ †Sussex Eye Hospital, Brighton
}

\begin{abstract}
Summary
Amiodarone is an antiarrhythmic agent unrelated to other drugs in current use. It has been little used in Britain, and no formal clinical trials have been possible because the drug has not been licensed by the Committee on Safety of Medicines. Nevertheless it has unique properties which can be valuable in the treatment of a wide spectrum of arrhythmias, particularly supraventricular tachycardias. Amiodarone has a slow onset of action and is cumulative. A sustained action is therefore achieved without the need for frequent maintenance dosage. Fifty patients have been treated with amiodarone in maintenance doses ranging from $\mathbf{2 0 0} \mathbf{~ m g}$ on alternate days to $\mathbf{2 0 0} \mathrm{mg}$ twice daily either alone, or in combination with conventional therapy. All were resistant to conventional therapy alone or could not be treated with usual agents because of unwanted drug effects. Of 27 patients with supraventricular arrhythmias, 18 were completely controlled and the other 9 were markedly improved. Six of 8 patients with recurrent life-threatening ventricular arrhythmias were well controlled symptomatically. Results were predictably less satisfactory in 15 high risk post-infarction patients with malignant arrhythmias and severe myocardial damage, but 6 were probably improved as a result of amiodarone. All patients on maintenance therapy for 3 months or more developed corneal microdeposits. None has any visual symptoms or other ocular defect, and treatment has not been curtailed as a result of this well recognized effect which is believed to be reversible and benign. Amiodarone can control patients with otherwise refractory arrhythmias including some which are lifethreatening. Formal clinical trials are needed to define accurately its future role in the prevention and treatment of serious rhythm disorders of the heart.
\end{abstract}

Correspondence: D. A. Chamberlain, M.D., F.R.C.P., Department of Cardiology, Royal Sussex County Hospital, Brighton, Sussex BN2 5BE.
Introduction

The introduction of $\beta$-adrenoceptor blocking drugs, membrane stabilizing agents, and calcium antagonists (Vaughan-Williams, 1970; Singh and Hauswirth, 1974) has led to striking improvement in the medical management of most cardiac arrhythmias over the past 15 years. There remains a small proportion of patients with rhythm disorders which cannot be controlled with conventional therapy because of inadequate or inappropriate therapeutic effect. Toxic and side effects limit the value of some drugs, while the route or frequency of administration make others inconvenient to use. The search for new and better antiarrhythmic agents therefore continues.

Amiodarone is an effective antiarrhythmic agent neither related in structure nor similar in effects to any other drugs in current use. Although it is not freely available in the United Kingdom, enthusiastic accounts of its value have appeared from other parts of Europe (Van Schepdael and Solvay, 1970; Vastesaeger, Gillot and van der Straeten, 1971; Coumel and Bouvrain, 1973) and from South America (Rosenbaum et al., 1974; 1976).

The authors now report their experience with amiodarone in 50 patients with serious arrhythmias which had proved refractory to conventional therapy. The results have been impressive, and in some cases life-saving.

\section{Clinical pharmacology of amiodarone}

Amiodarone is a benzofuran derivative structurally similar to thyroxine (Charlier et al., 1968) (Fig. 1). It was first introduced as an antianginal agent (Vastesaeger, Gillot and Rasson, 1967), having been shown as increasing coronary blood flow (Charlier et al., $1967 ; 1968)$ and decreasing myocardial oxygen consumption (Charlier et al., 1968). The mode of action as an antiarrhythmic agent may follow from 
prolongation of the action potential in atrial and ventricular muscle without changes in the membrane resting potential (Vaughan-Williams, 1970; Singh and Vaughan-Williams, 1970). Amiodarone also diminishes the maximum rate of rise of the action potential and therefore slows conduction velocity (Rosenbaum et al., 1976).

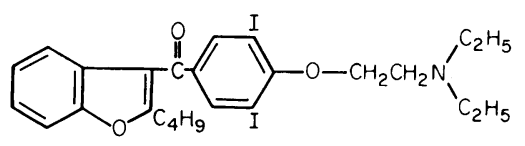

FIG. 1. Structural formula of amiodarone.

In the intact heart, any delay in repolarization is manifest by prolongation of the QT interval (Facquet et al., 1970; Pritchard, Singh and Hurley, 1975; Rosenbaum et al., 1976). Electrophysiological studies show an increase in effective refractory period. Automaticity of pacemaker cells is not usually significantly reduced (Facquet et al., 1970) although atropine-resistant bradycardia can occur on maintenance therapy (Charlier et al., 1968; Facquet et al., 1970; Pritchard et al., 1975). Slowing of conduction may rarely potentiate pre-existing atrioventricular block (Rosenbaum et al., 1976) and unmask latent bundle branch block (Chiale et al., 1975). Amiodarone has also been shown as having a marked anti-fibrillatory effect (Charlier et al., 1968; Singh and Vaughan-Williams, 1970).

The appearance of microdeposits in the cornea is the most common side effect of therapy (François, 1968; Miller, 1969; Chiale et al., 1975) and may occur after only 14 days of treatment, perhaps as a result of lacrimal secretion (Rosenbaum et al., 1976). The epithelial changes are reversible by stopping therapy, and they usually cause no impairment of vision.

Cases of hypothyroidism (Massin et al., 1971; Barrillon and Himbert, 1971; Guinet et al., 1972) and hyperthyroidism (Jonckheer et al., 1973; Savoie et al., 1975) have occurred during treatment with amiodarone. The mechanisms for these effects are not well understood but the iodine content of amiodarone increases thyroxine production. An elevation of serum thyroxine concentration and a decrease in serum triiodothyronine concentration occur even in euthyroid patients (Pritchard et al., 1975). Skin disorders such as photodermatitis (Rosenbaum et al., 1976) and melanodermatitis (Geerts, 1971) are thought to be related to deposition of crystals. Erythema nodosum (Rosenbaum et al., 1976) and toxic erythematous drug reactions occur rarely. Other reported side effects include tremor of Parkinsonian type (Lhuillier and Gouin, 1972) and one case of peripheral neuropathy (Lustman and
Monseu, 1974). Unlike most other antiarrhythmics with a therapeutic range close to toxicity, it has a wide margin of safety (Rosenbaum et al., 1976). Experimentally the $\mathrm{LD}_{50}$ for amiodarone is ten times the therapeutic dose when given i.v. (Charlier et al., 1962). Acute toxicity after large oral doses has not been reported.

\section{Patients}

This report concerns the first 50 patients the authors treated with maintenance amiodarone. The results were assessed up to 31 July 1977. Selection has been based on clinical need, and the drug has been used only after failure of conventional antiarrhythmic therapy or in a few cases because other agents seemed inappropriate. Amiodarone was prescribed more readily for supraventricular than for ventricular arrhythmias. The follow-up period for the group under review ranged from 6 months to nearly 4 years. No clinical trials certificate is yet available in Britain so formal placebo-controlled studies have not been attempted.

The patients have been divided retrospectively into several groups based on the clinical diagnosis or the dominant arrhythmia for which treatment was given: 3 with Wolff-Parkinson-White (WPW) syndrome, 2 with paroxysmal supraventricular tachycardia, 2 with atrial flutter, 8 with rapid refractory atrial fibrillation, 5 with paroxysmal atrial fibrillation, 6 with tachycardia-bradycardia syndrome, one with multifocal atrial tachycardia, 8 with idiopathic ventricular arrhythmias, and 15 patients with serious ventricular arrhythmias after infarction.

\section{Dose of amiodarone}

In nearly all instances the initial dose was $200 \mathrm{mg}$ thrice daily, reduced to $200 \mathrm{mg}$ twice daily in the second week, and $200 \mathrm{mg}$ daily in the third. Subsequent maintenance doses depended upon therapeutic response and varied from $200 \mathrm{mg}$ on alternate days to $200 \mathrm{mg}$ twice daily. A few critically ill patients received $750 \mathrm{mg}$ i.v. in three divided doses each day; oral treatment was substituted as soon as possible.

\section{Results}

The results for the groups described above are shown in Tables 1, 2 and 3. Rosenbaum's system (Rosenbaum et al., 1976) has been used to classify the patients' response to treatment. Excellent (E) represents total symptomatic improvement or unequivocal ECG evidence of abolition of arrhythmias on 24-hr monitoring. Good (G) indicates $>50 \%$ subjective improvement. Poor $(P)$ is used if the improvement in symptoms is judged $<50 \%$.

Of the 27 patients with supraventricular arrhythmias, $18(66 \%)$ had excellent responses, and $9(33 \%)$ had good responses. These satisfactory results were 
achieved with doses of $200 \mathrm{mg}$ daily in most instances, but 2 patients received $200 \mathrm{mg}$ twice daily and 5 required $200 \mathrm{mg}$ on alternate days only. Of 8 patients with idiopathic ventricular arrhythmias, 5 had excellent results, one was classed as good and 2 died after 2 weeks and 2 months respectively without obvious benefit. Four of this group received $200 \mathrm{mg} /$ daily and the others $200 \mathrm{mg}$ twice daily.

The results were less satisfactory in the 15 high-risk, post-infarction patients with recurrent ventricular arrhythmias. Seven died within 8 weeks, and treatment was stopped in 2 . Of the remainder, 3 had an excellent response and 3 a good response with doses of $200-400 \mathrm{mg}$ daily.

\section{Toxicity}

None of the patients has had serious symptoms of toxicity. A few have experienced transient nausea with the initial higher doses. A rash occurred in 2 patients. One died of massive myocardial infarction and the drug was discontinued in the other.

Of the 30 patients examined ophthalmologically by 31 July $1977,28(93 \%)$ had evidence of corneal deposits. No changes are visible other than by slit-lamp microscopy and the majority take the form of faint grey granular linear deposits in the epithelium, and possibly Bowman's membrane. The earliest changes occur at the junction of the middle and lower thirds of the cornea in the site of and sometimes in the presence of a Hudson's line. Progression sees the development of fine curving lines radiating upwards and outwards in the manner of a fan from the central point of the initial line, sometimes resulting in a whorl-like pattern. The lines occasionally reach the limbus and only seldom radiate downwards. In 3 cases the changes took the form of diffuse granular deposits rather than the linear pattern. They sometimes became apparent as early as one month after the first exhibition of the drug and showed evidence of dose dependency and reversibility on withdrawal or reduced dosage of the drug. The 2 patients without changes were seen only 1 and 3 months after starting treatment and will probably develop some changes if the drug is continued. Vision has not been affected in any patient and the changes are generally symmetrical. No other symptoms or signs have been noted and, in particular, no macular lesions found. In the patients in whom it has been tested, colour vision remains unimpaired but no electro-diagnostic or angiographic studies have been undertaken. The changes resemble those seen in chloroquine keratopathy (Hobbs and Calnan, 1958), chlorpromazine toxicity (Johnson and Buffaloe, 1966) and the recently described keratopathy in some patients treated with clofazimine (a phenazine derivative) (Walinder, Gip and Stempa, 1976). Therapy has not been discontinued in any patient because of this effect although all remain under regular ophthalmological supervision.

\section{Discussion}

The antiarrhythmic effects of amiodarone probably depend upon prolongation of action potential and refractory period in the myocardium rather than on any dominant action on the specialized conducting system. This makes amiodarone of particular value for arrhythmias which depend upon rapid propagation of wave fronts within myocardial tissue especially of atria or anomalous pathways. It can also be used as an adjunct to conventional drugs which act on pacemaker and conducting tissue. Moreover some of its properties make it unusually attractive as an antiarrhythmic agent. Firstly, the spectrum of activity is wide, although atrial arrhythmias are more readily controlled than those arising in the ventricles. Secondly, myocardial depression from therapeutic doses is slight and heart failure is evidently not an important contra-indication to its use (Charlier et al., 1968; Barzin and Fréson, 1969; Singh et al., 1976). Thirdly, serious toxicity is rare and overdosage by the oral route is not hazardous (Rosenbaum et al., 1976). Finally it has a sustained action: doses once daily or on alternate days may maintain effective tissue levels of the drug. Therapeutic activity can continue for weeks after treatment has stopped (Broekhuysen, Laruel and Sion, 1969; Rosenbaum et al., 1976).

The cumulative action depending on slowly increasing tissue levels has one disadvantage - effects cannot be obtained rapidly even with intravenous use. It has been found that 2-7 days are required for clinical effects, and these probably increase over several weeks. Amiodarone is therefore of little value in emergencies although it may be given appropriately with a thought to subsequent management if the patient can be sustained over the first critical days.

Coumel and Bouvrain (1973) showed that amiodarone was effective for a variety of atrial and ventricular arrhythmias, including reciprocating tachycardias and refractory atrial fibrillation complicating the WPW syndrome. Their observation led to the present authors' first use of amiodarone later the same year for a patient with WPW syndrome who was unresponsive to other therapy (Chamberlain and Clark, 1977). Rosenbaum et al. (1974) amply confirmed the near-specific effect in pre-excitation syndromes and have reported total suppression of arrhythmias in all 27 patients treated with the drug. Other groups have had similar experiences (Wellens et al., 1976).

Most cases of supraventricular tachycardia depend upon reciprocating wave fronts within dual 


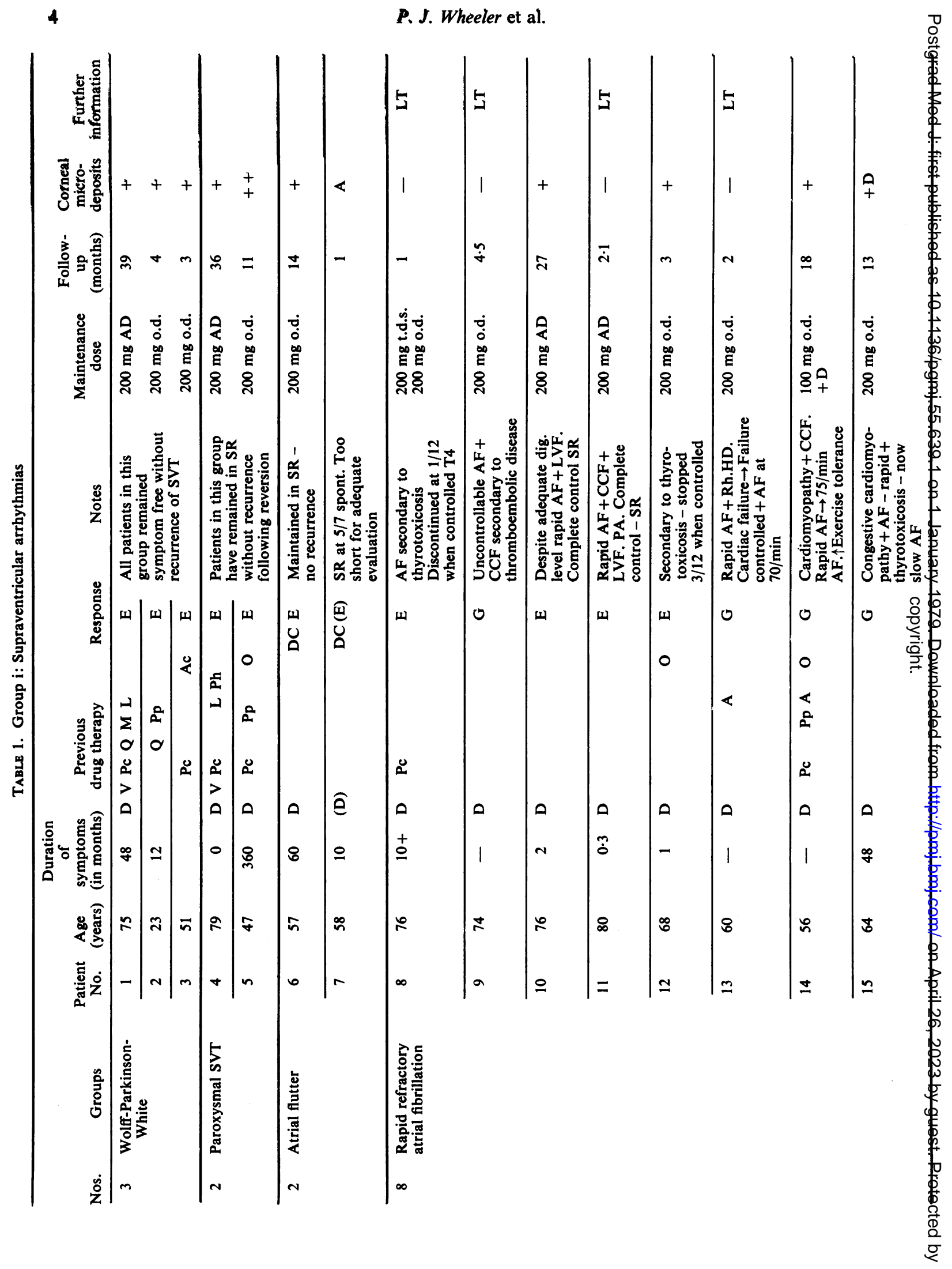




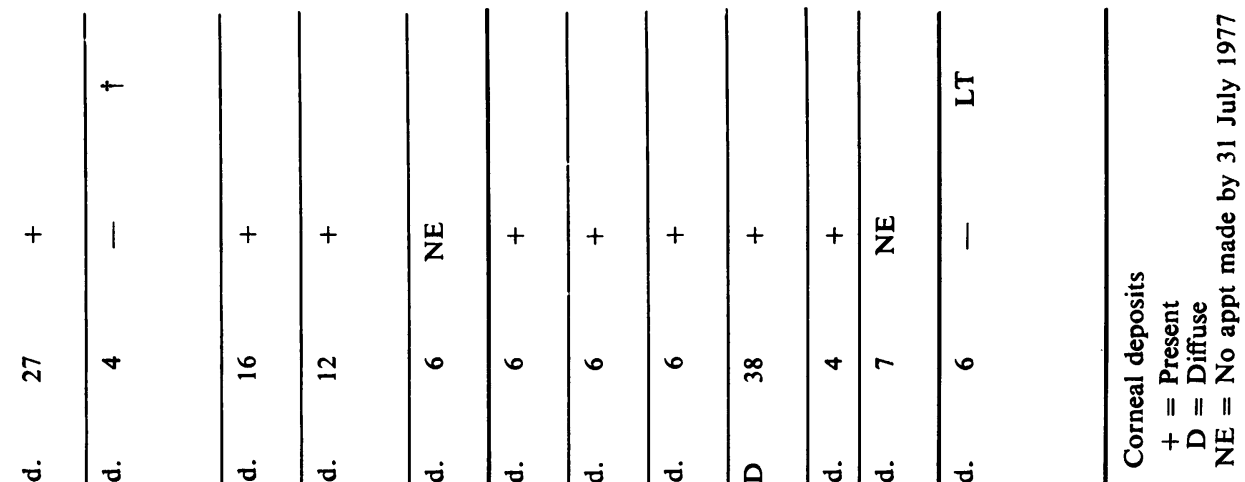
(5)

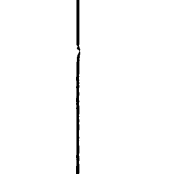
s

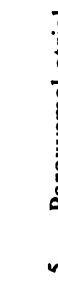

可

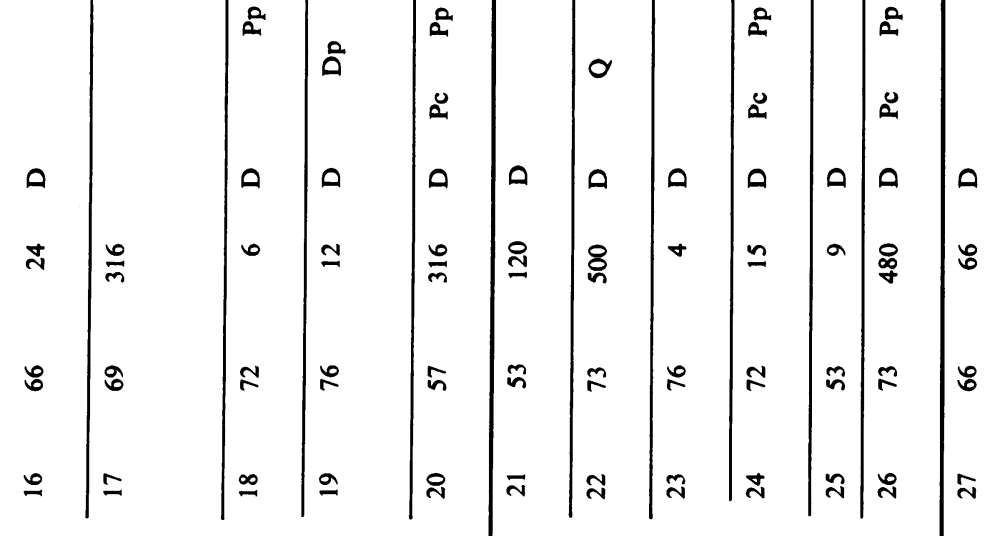

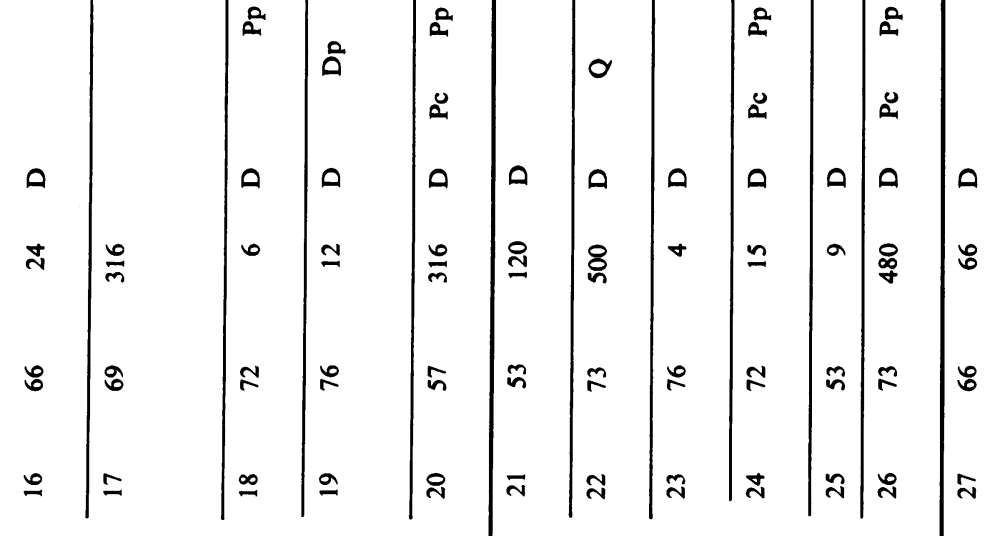
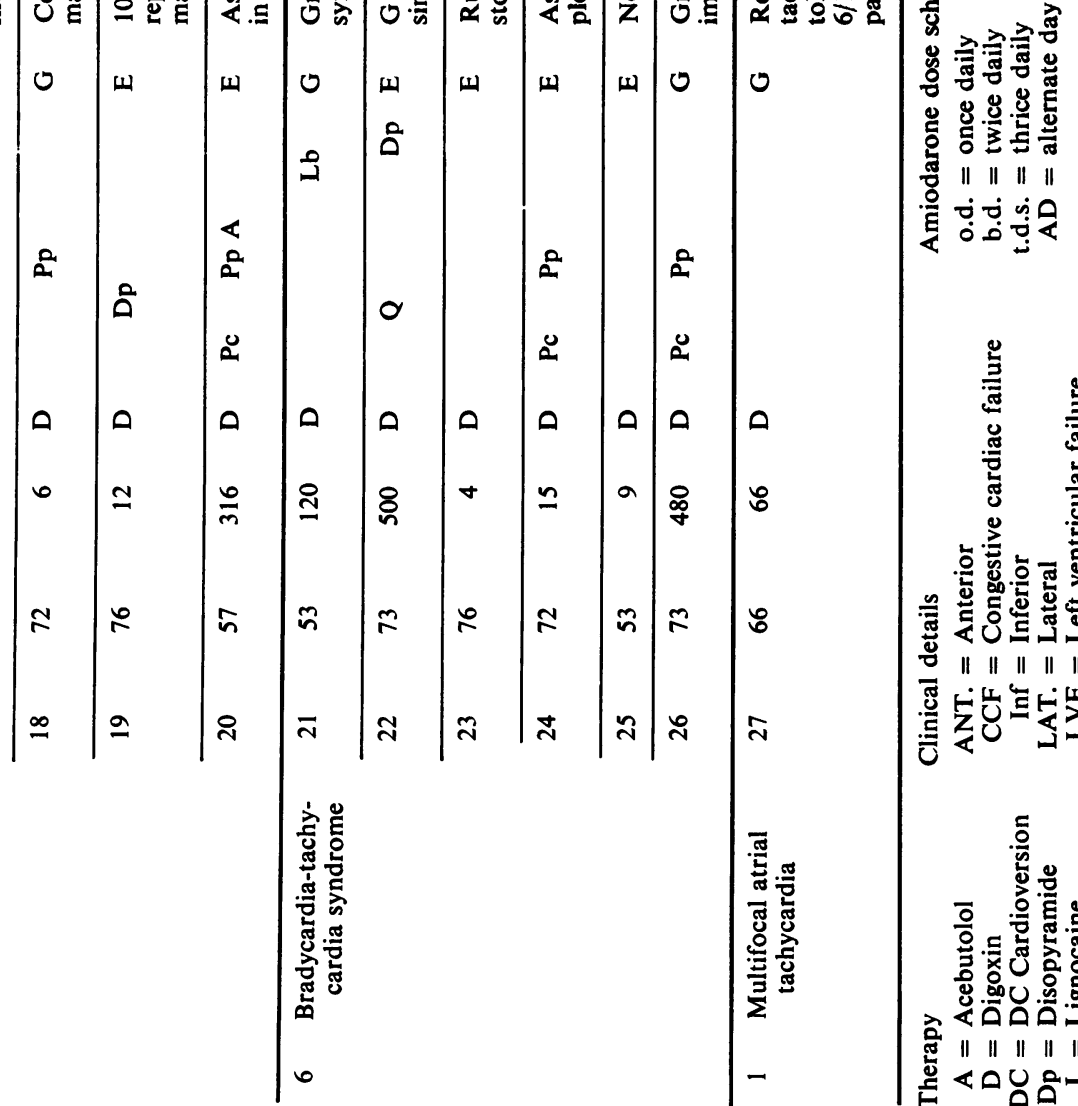

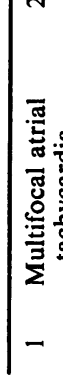

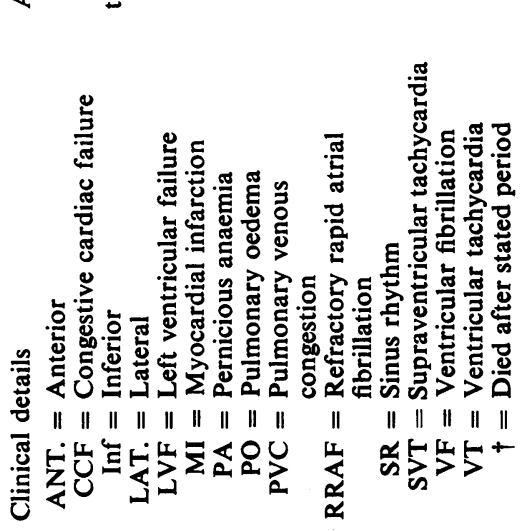

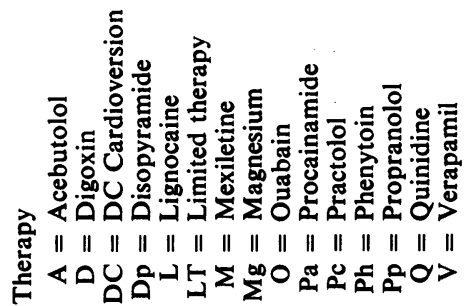


P. J. Wheeler et al.

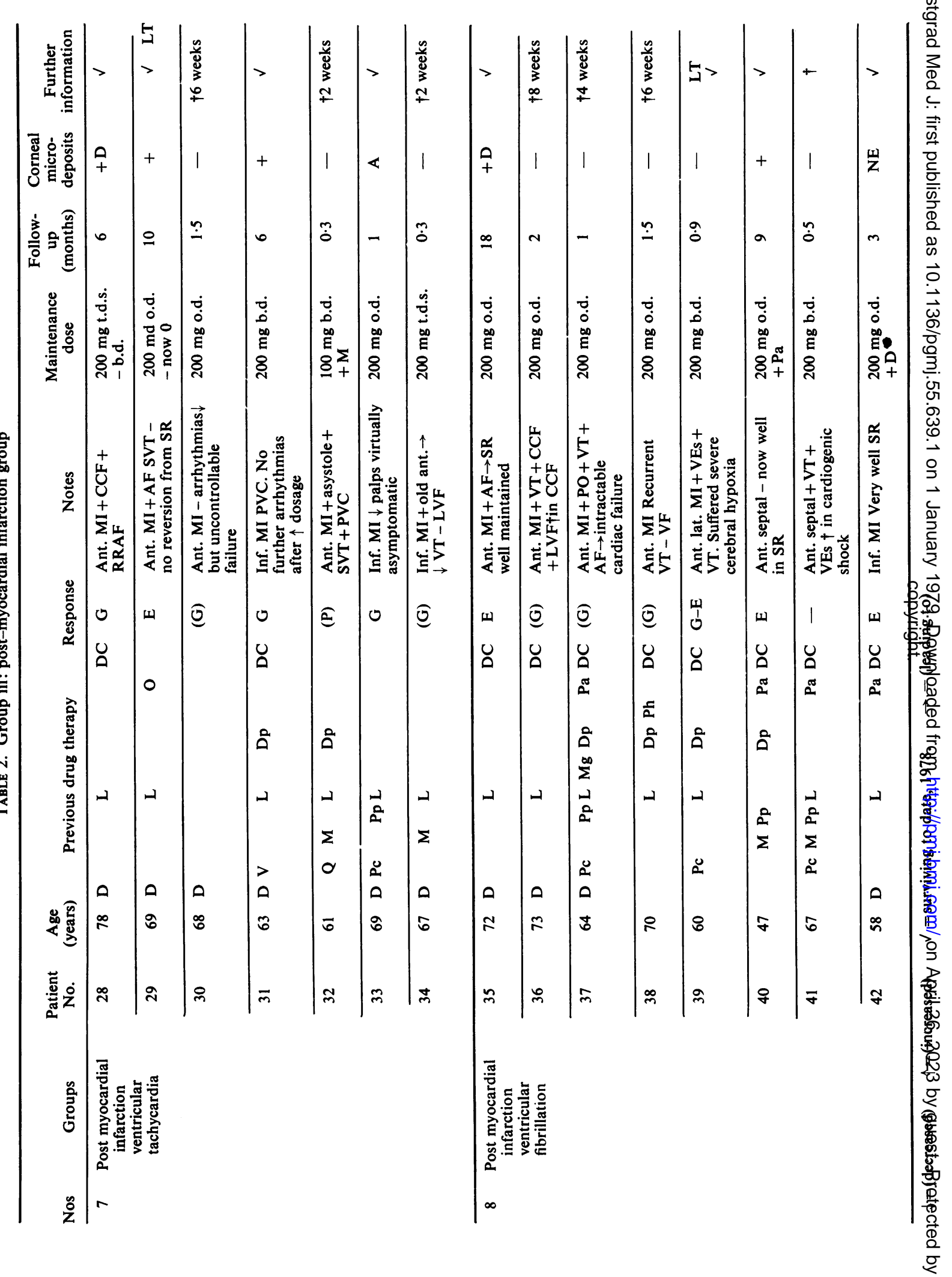




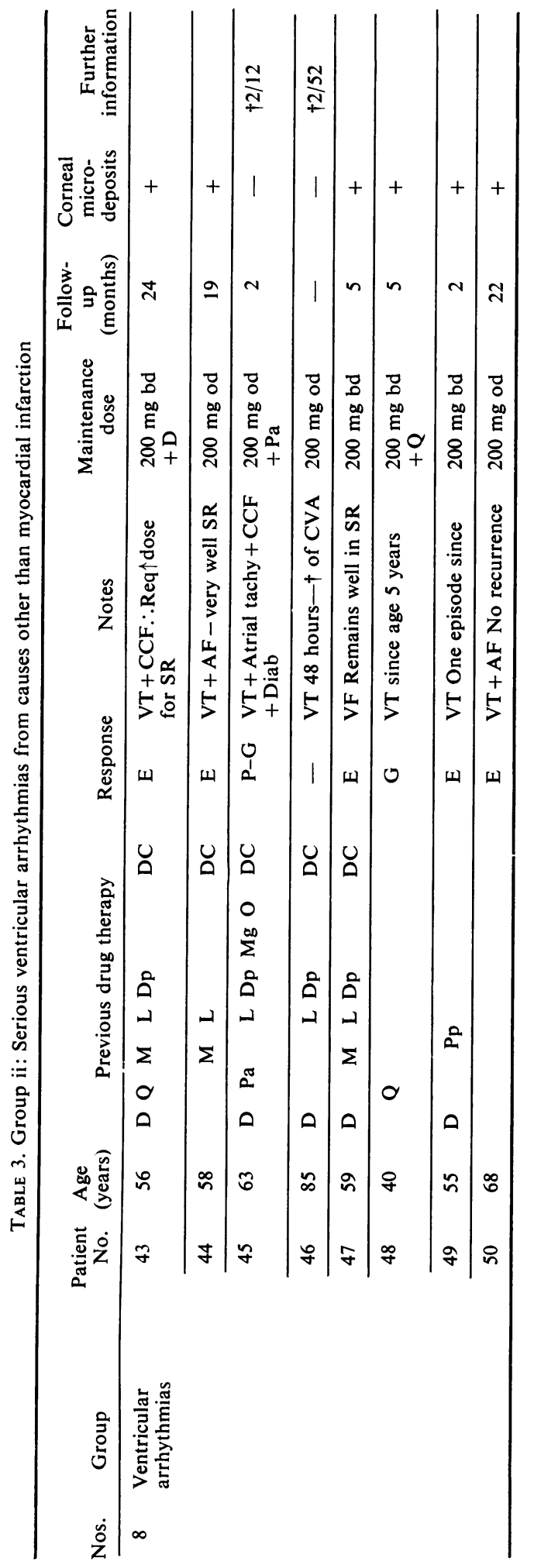


pathways involving both atria and ventricles (Bigger and Goldreyer, 1970) or sometimes only atria and the atrio-ventricular node (Kistin, 1965). Dual pathways can exist within the nodal-His system but in an unknown proportion of patients the retrograde pathway is anomalous, lying outside the normal conducting tissue. If pre-excitation does not occur during antegrade conduction, the mechanism is not apparent from conventional electrocardiograms (Krikler, 1974). Thus we do not know how many patients with supraventricular tachycardia have anomalous pathways and may therefore be uniquely responsive to amiodarone. Rosenbaum et al. (1976) reported excellent therapeutic effects in $96 \%$ of patients with diverse supraventricular arrhythmias; some may have had inapparent WPW syndrome or related conditions. The small number of patients in the present series with supraventricular tachycardia reflects the relatively high success rate with conventional therapy which made amiodarone unnecessary, and is not due to any reluctance on the authors' part to use this drug in this group of patients.

The aim of treatment for atrial fibrillation may be either the control of ventricular rate or, alternatively, the prevention of recurrent episodes of the arrhythmia. Cardiac glycosides and $\beta$-adrenoceptor blocking agents are the mainstay of current management, but problems do occur. Paroxysmal atrial fibrillation is not always preventable, and the ventricular rate may be fast and obtrusive at the start of a rhythm change even in a digitalized patient. Ventricular response in established fibrillation may remain fast despite therapy, particularly with underlying abnormalities such as thyrotoxicosis or recurrent thromboemboli. For both groups, $\beta$-adrenoceptor blocking agents may be contra-indicated because of heart failure or asthma, and full therapeutic levels of digitalis itself may be poorly tolerated in a few people. It was for reasons such as these that amiodarone was prescribed for some patients with uncontrolled paroxysmal or rapid refractory atrial fibrillation. Good or excellent responses were achieved in all 13 patients and amiodarone is now regarded as having been of special value in this group of patients.

The tachycardia-bradycardia syndrome deserves special mention. In this condition, symptoms are caused by paroxysms of supraventricular tachycardia or atrial fibrillation, but also by abrupt slowing of the heart rate, sometimes with brief asystolic pauses. Both are manifestations of underlying sinus node disease. Management is particularly difficult because drugs which tend to control the fast rhythms tend also to make the bradycardia worse, and vice versa. Implantation of a pacemaker may be necessary as part of effective management in severe cases. The authors were surprised at the response to amio- darone in 6 patients: 4 became symptom-free and 2 were greatly improved. Abolition of the tachycardia by a drug which does not itself have a profound effect on automaticity or conduction within normal pathways may offer new hope for effective medical therapy of this syndrome, because bradycardia is particularly likely to be severe following abrupt cessation of a rapid rhythm. The authors stress that pacing remains mandatory for patients with serious episodes of syncope and their experience is, so far, insufficient to define the proper role of amiodarone in this difficult group of conditions.

The authors have used amiodarone in only a few patients with recurrent ventricular tachycardia when other drugs have provided ineffective control. They have the impression that it may be useful, but 4 of their 8 cases have required $400 \mathrm{mg}$ daily which is a dose level at which corneal deposits may become troublesome. Rosenbaum et al. (1976) claimed success in $82 \%$ of patients using $200-400$ $\mathrm{mg}$ daily but their cases had not necessarily proved difficult to control with other therapy. The authors believe that amiodarone is less effective for ventricular arrhythmias than for supraventricular ones, and larger doses will be required with a higher risk of unwanted effects.

Fifteen high-risk patients who were experiencing malignant arrhythmias after infarction were treated; all had had ventricular tachycardia or ventricular fibrillation. A few patients had paroxysmal atrial fibrillation, but the authors were reluctant to use digitalis because of its possible adverse effect on ventricular irritability. Most had serious myocardial dysfunction complicated by pulmonary oedema. Conventional antiarrhythmic treatments had either proved ineffective or were contra-indicated because of a negative inotropic effect. Seven patients died, and the drug was discontinued in 2 when an unstable rhythm was thought to have settled. Only 4 patients have been followed on amiodarone. Without a clinical trial for patients of this type, it is impossible to know whether or not prognosis is improved.

None of the present patients has had serious symptoms of toxicity. A few have experienced transient nausea with the initial higher doses, especially those who were treated with digoxin concurrently. The corneal microdeposits cause most concern but it is believed that these symptoms are reversible.

The patients treated with amiodarone alone or in combination with other agents have all been resistant to or unsuitable for conventional therapy. In this context the results were remarkable, particularly for supraventricular arrhythmias: in all 27 patients the response was judged either excellent or good. 
The results were assessed partly on objective and partly on subjective criteria, but a powerful placebo effect is unlikely in a group previously disappointed by medical therapy. Formal clinical trials have not been possible in this country because no licence has been obtained, but on the basis of their routine clinical experience and of experience obtained overseas the authors regard controlled studies in selected groups as being a pressing necessity. Amiodarone (or a similar derivative) is likely to find an important place in the therapy of several types of arrhythmia which can be difficult to manage with conventional antiarrhythmic agents.

\section{References}

Barrillon, A. \& Himbert, J. (1971) Amiodarone et thyroïde. Presse médicale, 33, 1498.

Barzin, J. \& Fréson, A. (1969) Essais cliniques de l'amiodarone dans les affections coronariennes. Bruxelles médical, 49, 105.

BIgGer, J.T. \& Goldreyer, B.N. (1970) The mechanism of supraventricular tachycardia. Circulation, 42, 673.

Broekhuysen, J., LARUel, R. \& Sion, R. (1969) Recherches dans la série des benzofurannes. XXXVII Étude comparée du transit et du métabolisme de l'amiodarone chez diverses espèces animales et chez l'homme. Archives Internationales de Pharmacodynamie et de Thérapie, 177 (2), 340.

Chamberlain, D.A. \& Clark, A.N.G. (1977) Atrial fibrillation complicating Wolff-Parkinson-White syndrome treated with amiodarone. British Medical Journal, 2, 1519.

Charlier, R., Baudine, A., Chaillet, F. \& Deltour, G. (1967) Recherches dans la série des benzofurannes. XXV Effets hémodynamiques de l'amiodarone chez le chien. Acta cardiologica, 22, 323.

Charlier, R., Deltour, G., Baudine, A. \& Chaillet, F. (1968) Pharmacology of amiodarone, an anti-anginal drug with a new biological profile. Arzneimittel-Forschung, 11, 1408.

Charlier, R., Deltour, G., Tondeur, R. \& Binon, F. (1962) Recherches dans la série des benzofurannes. VII Étude pharmacologique préliminaire du butyl-2(diiodo-3', 5'-béta - N-diéthylaminoéthoxy - 4' - benzoyl) - 3 - benzofuranne. Archives Internationales de Pharmacodynamie et de Thérapie, 139, 255.

Chiale, P.A., Levi, R.J., Halpern, M.S., Elizari, M.V. \& Rosenbaum, M.B. (1975) Efecto de diferentes drogas antiarritmicas sobre un caso de bloqueo de rama intermitente. Medicina. Buenos Aires, 35, 1.

Coumel, P. \& Bouvrain, Y. (1973) Étude clinique des effets pharmacodynamiques et antiarythmiques de l'amiodarone. Journal des Agrégés, 6, 69.

Facquet, J., Nivet, M., Grosgogeat, Y., Alhomme, P. \& VACHON, J. (1970) L'influence de l'amiodarone sur le rythme cardiaque et l'électrocardiogramme. Thérapie, 25, 335.

Françols, J. (1968) Cornea verticillata. Bulletin des Sociétés d'ophtalmologie de France, 150, 656.

GeERTS, M.L. (1971) Amiodarone pigmentation - an electron microscopic study. Archives Belges de Dermatologie et de Syphiligraphie, 27 (4), 339.

Guinet, P., Pousset, G., Brière, J. \& Grand Smith BIANCHI, G. (1972) Contribution à l'étude du myxoedème à l'iode à propos d'un cas à l'amiodarone. Revue Française d'Endocrinologie Clinique, Nutrition et Métabolisme, 13 (3), 229.
Hobbs, H.E. \& Calnan, C.D. (1958) The ocular complications of chloroquine therapy. Lancet, i, 1207.

Johnson, A.W. \& Buffaloe, W.J. (1966) Chlorpromazine epithelial keratopathy. Archives of Ophthalmology, 76, 664.

Jonckheer, M.H., Blockx, P., Kaivers, R. \& Wyffels, G. (1973) Hyperthyroidism as a possible complication of the treatment of ischaemic heart disease with amiodarone. Acta cardiologica, 28, 192.

Kistin, A.D. (1965) Atrial reciprocal rhythm. Circulation, 32, 687.

KRIKLER, D.M. (1974) A fresh look at cardiac arrhythmiasCardiac electrophysiology. Lancet, i, 851 .

Lhuillif, M. \& Gouin, B. (1972) Amiodarone et tremblement. Nouvelle Presse médicale, 27 (1), 1844.

Lustman, F. \& Monseu, G. (1974) Amiodarone and neurological side effects. Lancet, i, 568 .

Massin, J.P., Thomopoulos, P., Karam, J. \& Savoie, J.C. (1971) Le risque thyroïdien d'un nouveau coronarodilatateur iodé: l'amiodarone (cordarone). Annales d'Endocrinologie, 32, 438.

Miller, M.H.A. (1969) Kératopathie consécutive au traitement par cordarone (chlorhydrate d'amiodarone). Bulletin des sociétés d'ophtalmologie de France, 69, 1059.

Pritchard, D.A., Singh, B.N. \& Hurley, P.J. (1975) Effects of amiodarone on thyroid function in patients with ischaemic heart disease. British Heart Journal, 37, 856.

Rosenbaum, M.B., Chiale, P.A., Halpern, M.S., NaU, G.J., Przybylski, J., Levi, R.J., Lazzari, J. \& Elizari, M.V. (1976) Clinical efficacy of amiodarone as an antiarrhythmic agent. American Journal of Cardiology, 38, 934.

Rosenbaum, M.B., Chiale, P.A., Ryba, D. \& Elizari, M.V. (1974) Control of tachyarrhythmias associated with Wolff-Parkinson-White syndrome by amiodarone hydrochloride. Amcric an Journal of Cardiology', 34, 215.

Savoie, J.C., Massin, J.P., Thomopoulos, R. \& Leger, F. (1975) Iodine-induced thyrotoxicosis in apparently normal thyroid glands. Journal of Clinical Endocrinology and Metabolism, 41, 685.

Singh, B.N. \& HauswirTh, O. (1974) Comparative mechanisms of action of antiarrhythmic drugs. American Heart Journal, 87, 367.

Singh, B.N., JewitT, D.E., Downley, J.M., KIRK, E.S. \& SONNENBLICK, E.H. (1976) Effects of amiodarone and L8040 novel antianginal and antiarrhythmic drugs on cardiac and coronary haemodynamics and on cardiac intracellular potentials. Clinical and Experimental Pharmacology and Physiology, 3, 427.

Singh, B.N. \& Vaughan-Williams, E.M. (1970) The effect of amiodarone, a new antianginal drug, on cardiac muscle. British Journal of Pharmacology, 39, 657.

Van Schepdeal, J. \& Solvay, H. (1970) Étude clinique de l'amiodarone dans les troubles du rythme cardiaque. Presse médicale, 78, 1849.

Vastesaeger, M., Gillot, P. \& Rasson, G. (1967) Étude clinique d'une nouvelle médication anti-angoreuse. Acta cardiologica, 22, 483.

Vastesaeger, M.M., Gillot, P.H. \& Van der Straeten, P. (1971) L'effet anti-arythmique de l'amiodarone. L3428. Bruxelles médical, 51 (2), 99.

Vaughan-Williams, E.M. (1970) Classification of antiarrhythmic drugs. In: Symposium on Cardiac Arrhythmias, Elsinore, Denmark, AB Astra, April 23-25, 449.

Walinder, P.E., GiP, L. \& STemPA, M. (1976) Corneal changes in patients treated with clofazimine. British Journal of Ophthalmology, 60, 426.

Wellens, H.J.J., Lie, K.I., BÄr, F.W., WeSdorP, J.C. Dohmen, H.J., Duren, D.R. \& Durrer, D. (1976) Effect of amiodarone in the Wolff-Parkinson-White syndrome. American Journal of Cardiology, 38, 189. 